\title{
CORRIGENDUM
}

\section{What is the best measure of adiposity change in growing children: BMI, BMI \%, BMI z-score or BMI centile?}

TJ Cole ${ }^{1}$, MS Faith ${ }^{2}$, A Pietrobelli ${ }^{3,4}$ and $\mathrm{M} \mathrm{Heo}^{5}$

European Journal of Clinical Nutrition (2005) 59, 807. doi:10.1038/sj.ejen.1602155

Correction to: European Journal of Clinical Nutrition (2005) 59, 419-425. doi:10.1038/sj.ejcn.1602090

Following publication of the above paper, the authors have identified an error in Figure 4. It is reproduced correctly below, with the axes now including zero. The authors apologize for any confusion this may have caused.

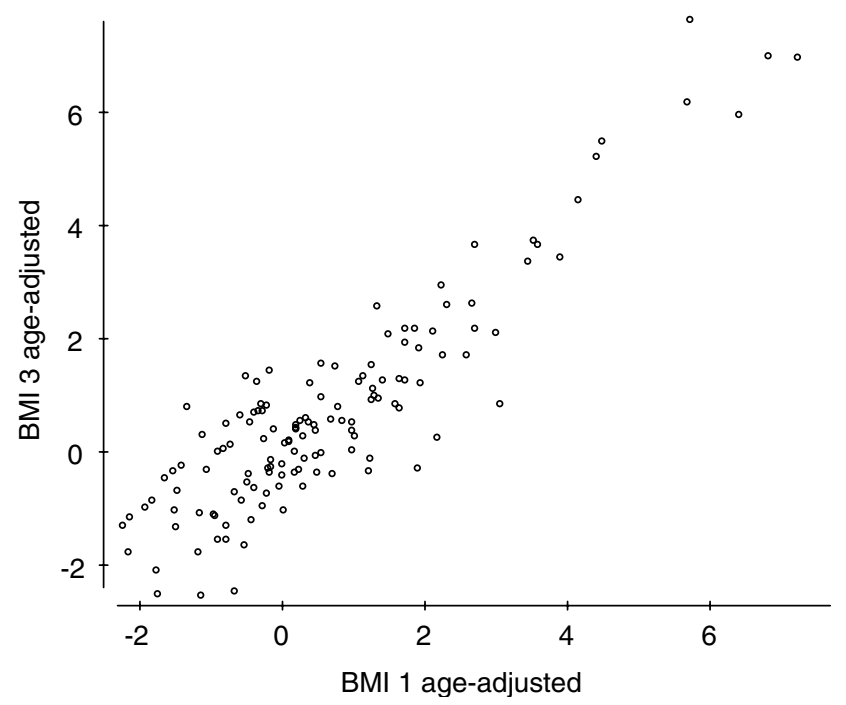

Figure $4 \mathrm{BMI}$ plotted against BMI in 135 subjects, both BMls adjusted for age. 